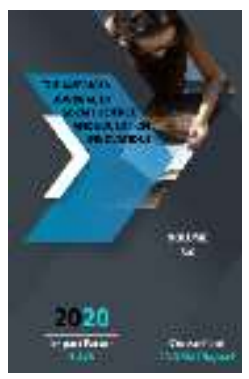

\title{
The Role Of Teachers' Cultural Awareness In Preparing To Work With Multicultural Students
}

Journal Website: http://usajournalshub.c om/index,php/tajssei

\author{
Narimanova Jamola Yuldashbayevna \\ Teacher At Uzbekistan State World Languages University, Tashkent City, Uzbekistan.
}

\section{ABSTRACT}

The main purpose of this article is for teachers to help students learn about different ethnic groups, cultures, languages, customs, values, lifestyles, ideas, views, identity, customs, rituals, rituals and symbols, show and check their movements, families in the community they teach. Teachers at the University of World Languages in Uzbekistan were interviewed to explore their insights and opinions about diversity. Teachers provide information on many methods, but they show that they do not really understand diversity. Teachers around the world reported trusting external sources such as guest speakers and students, but were unable to benefit from their colleagues, parents, and their own experiences. This article is based on the study of multicultural consciousness and awareness of different cultures by educating multicultural students. The fact that language and culture are interconnected, that they are inseparable, that they are inseparable, that the study of language also requires the study of the interrelationships of cultures. The close interrelationships between culture and language can be used to enhance social cohesion and credibility in areas where cultural superstition, political and religious affection are prevalent. Therefore, the practice of language teaching should be used to eradicate cultural consciousness, identity, stereotypes and improve intercultural understanding, universal values, customs, traditions, rituals that serve the peaceful coexistence of different people in the world Possible.

\section{KEYWORDS}

Culture, communication, intercultural communication, cultural phenomenon, cultural knowledge, cultural perception, communication techniques, multiculturalism. 


\section{INTRODUCTION}

Teachers around the world are confronted with students with a variety of backgrounds, including skills, culture, socioeconomic status, religion, and more. Regardless of the diversity group that teachers face, teachers need to be aware and willing to learn about diversity. In some parts of the world, there are more and more students with different teaching cultures. This is especially true in the United States. However, as the number of students in the United States changes rapidly, the teaching staff is largely white, female, middleclass, and inherited from European heritage (Aaroe \& Nelson, 2000; Allen \& Porter, 2002; Sleeter, 2001). [1] Many researchers believe that there is a link between children's failure in school and those who teach them (e.g., Au \& Blake, 2003; Benson, 2003; Ukpokodu, 2004). [24] The results of this study show that some educators have limited cultural knowledge and face the problem of diversity, so they need the information, skills, and knowledge needed to effectively teach children of different backgrounds. have no skills. It is well known that in the United States, students with different cultures receive less positive education than their peers (Fryer and Levitt, 2006; Sanders, 2000). There are many home conditions and schoolbased variables that affect the academic performance of these students. Variables in the home environment, such as parental involvement and socioeconomic status, have contributed to the success and activism of minority children in school (e.g., Fantuzzo, LeBoeuf, Rouse, \& Chen, 2012). School-based variables, including teacher quality and school climate, have also been found to be strongly correlated with student learning (e.g., Williams, 2011). Teacher quality is a school variable that is often used in the study of its impact on academic achievement. The link between teacher quality and student achievement may explain why minority students do not perform as well as their white peers in the United States. For example, Irvine (2003) found that even after preschoolers took coursework in multicultural education, they had negative beliefs for non-white students and had low expectations for success. In addition, McCaun and Weinstein (2008) found that teachers 'expectations of African-American and Latin students were much lower than those of white students of the same level. Becerra (2012) found that white teachers who did not understand Latin culture were the main reason for the difference in achievement. Although there are differences in the attitudes of parents and teachers towards education and the role of teachers, research has shown that some parents have lost confidence in schools (Good, Masewicz , \& Vogel, 2010). Furthermore, Sternberg, Lipka, Newman, Wildfeuer, and Grigorenko (2007) argue that many teachers do not understand the importance of incorporating socio-cultural contextual and practical knowledge as a way to enhance their students 'academic achievement.

In New Zealand, Rubie-Devies (2010) emphasizes that teachers with high demands tend to form positive learning communities and that their attitudes toward their students are positive. Rubie-Devies (2006) also found that students made great strides in learning with teachers who had high expectations of students. On the other hand, students who are accompanied by teachers with low expectations are more motivated to read. Similarly, Boer, Bosker, and Werf (2010) found that in the Netherlands, there is a correlation 
between teacher expectation and student long-term school performance. The great impact of teachers 'knowledge and quality on student learning requires our attention more than ever with the changing and evolving student population. To better meet the needs of different types of students, all schools need to be culturally responsive. But implementing a curriculum on diversity is not difficult because of the fear, uncertainty, or inconvenience of many teachers. Teachers 'beliefs influence and influence their teaching practices, and diversity becomes a barrier to the integration of the curriculum (Van Hook, 2002). Van Hook says some teachers find it difficult to discuss sensitive topics in the classroom and do not recognize and accept diversity. Moreover, it is difficult for many educators to recognize that their personal views consciously and unconsciously shape and overshadow relationships with children and their families. However, in order to develop a strong personality and meet the diverse needs of children, teachers need to be aware of culturally responsive teaching if they want to meet and work with all children (Gay, 2010; Hein, 2004; Villegas and Lucas, 2002). [13-18]

\section{THEORETICAL BASIS}

Culture- Responsive teaching means meeting the scientific and social needs of culturally diverse students (Gay, 2000; Howard, 2001; Ladson-Billings, 1994). Culturally influenced practices are based on the belief that teachers should be fully aware of the local heritage, language, and culture in their area of residence. This knowledge is critical to the development of culturally healthy students and communities and is important for identifying relevant qualities and practices related to culture-responsive teaching (Ladson-Billings, 1994). Jackson (1994) believes that most educators already use some teaching methods that are appropriate for development, but do not recognize them as a method that can be used to develop multicultural education. He argued that teachers need ways to recognize and use students 'different strengths. He outlined seven strategies that support culturally responsive pedagogy:

\section{Strategy 1: Build trust}

Teachers need to work with their students to maintain trust. Trusted relationships allow teachers to improve students and encourage them to higher levels of knowledge and help students take risks they do not accept (Jackson, 1994). Confidence between teacher and student is important as students develop their learning experiences. The key features and elements of a trusting relationship begin with knowing students 'names and pronouncing them correctly, exploring their family's heritage with students, and sharing the information learned with others (Jackson, 1994). Listening is the key to building trust with students (Brown \& Skinner, 2007). Listening helps the teacher understand the student's words and adds value to the beginning of the relationship. Getting to know the culture and traditions of students and their families is very important in building trust with students.

\section{Strategy 2: Becoming culturally literate.}

There are no dumb students. Most students work hard and try to do their best. However, the gap in specific cultural knowledge is important and very serious, which can affect students 'achievement in school. Knowing a game, a popular movie, or a TV show may seem trivial, but it's a sign of a huge challenge: not being able to collect the privileged cultural characters in a larger American life. 
Recognizing that students of different backgrounds need to be multicultural or bidialectic to adapt to most schools, teachers need to be able to adapt their students 'language, values, social traditions, and teaching methods to should strive to learn about (Jackson, 1994). Webster, Wiles, Civil, and Clark (2005) discuss the concept of using a third space to teach students of other cultures. The third space is defined as between the traditional models of knowledge and teaching in the West and the methods of knowing, studying, and existing local culture (Webster and Lipka, 2004; Webster et al., 2005). The use of a culturally based curriculum that combines knowledge of academic content with local cultural knowledge is the first step in creating a third space. However, it is not enough to use only a culturally responsive curriculum; teachers and students should work together to create cultural norms that represent all students for their classes. These new cultural norms require each member of the class to be bicultural or bidialectic in order to succeed.

\section{Strategy 3: Create a repertoire of learning strategies.}

In general, students of mainstream culture in Western countries learn independence, competition, the ability to sit for long periods of time, process linear and logical style, understand abstract ideas and concepts without using clear ideas, and follow verbal instructions (Cartledge \& Kiarie, 2001; Miles \& Stipek, 2006; Shade, 1982). However, students who are culturally diverse are often more dependent on the field (Ramirez and Caseaneda, 1974), value family or group identity rather than physical activity and independence (Hillard, 1989). Achieving all learners in different classes today requires teachers to have a complete repertoire of learning strategies. Teachers must have sufficient repertoire to meet the individual needs of students. Different learning strategies are very important, especially when working with young children, as this is one of the most appropriate and effective developmental tactics.

\section{Strategy 4: Use effective methods of asking questions}

The way teachers ask their students can affect students 'motivation, inspiration, and ability to learn. When teachers primarily ask students to remember and ask topical questions, teachers limit access to knowledge and content (Good \& Brophy, 2007). Teachers often blame students for their abilities, motivation, or inadequate support of the family (Osborne, 1996). Advanced students, on the other hand, get more questions and are asked questions that require critical thinking; Thus, increasing their educational opportunities. Teachers need to understand that high-level thinking questions are crucial to developing all students 'analytical and evaluative skills. They need to convey to students that their analysis, synthesis, and evaluation efforts are valuable. They should also allow students to see themselves as knowledge producers instead of consumers of knowledge (Jackson, 1994).

\section{Strategy 5: Provide effective feedback.}

Teachers 'feedback is critical to student success, and they vary by gender and race (Good \& Brophy, 2007). Students of color and girls of color receive feedback based on their personality, the cleanliness and appearance of their work, while the opinions of whites focus on academic achievement and action. Jackson (1994) teaches students that all students should receive feedback that is specific to their learning objectives, emphasizing the 
positive aspects of their work, and how to correct mistakes to improve the quality of their work. Teachers who implement culturally effective strategies take the time to analyze the quality of the feedback they give to students and know the culture of the students in presenting that feedback.

\section{Strategy 6: Analysis of textbooks}

Many educators teach about different cultures through celebrations, entertainment, and cultural artifacts from around the world, such as food and clothing. However, this is often seen as a tourist approach. While the tourist approach is interesting to students, it does not allow them to deal with everyday problems and experiences in life (DermanSparks, 1989; 1993; Jones and Derman-Sparks, 1992). Derman-Sparks (1989) also argues that a tourism multicultural curriculum does not enhance students 'understanding and empathy for our common humanity.

Conversely, a fully developed and integrated culturally responsive curriculum may benefit from similar activities, but seeks to avoid the risk of a tourist approach. Banks (1997) argue that teachers need to implement cultural criteria to evaluate classroom materials, instruction, and activities. Cultural criteria may include: assessing whether cultural and ethnic materials and activities accurately reflect the values or feelings of the group; ensuring that stories and books, especially fiction books, contain ethnic and cultural characters who are considered strong, moral, good, and wise; destruction of any ethnic and cultural material that conveys racist concepts, phrases or words; and the use of only historically accurate factual data (Jackson, 1994; Lake \& Lin, 2004; Riehl, 1993).

\section{Strategy 7: Establish a positive relationship between home and school.}

Confidence between parents and teachers is an important part of students 'learning experiences. Home-school collaboration has been shown to be a key contributor to improving trust in schools (Galindo \& Sheldon, 2012). Establishing positive relationships with families is critical for students who are found to have culturally diverse and disproportionate behaviors for marginalized students. Inviting families to school, meeting with extracurricular families, providing flexible meeting times and schedules, and asking families to increase their cultural knowledge to increase the number of classes are some of the strategies used by teachers.

Parents of language minority groups may have different attitudes toward school (DanielWhite, 2002; Sy, 2006). However, when these parents are actively involved in their children's schools, they can help them achieve higher levels of academic motivation and performance (St. Clair and Jackson, 2006). When parents are actively involved in school activities and understand them, they are able to help and support their child's learning activities, regardless of their ethnic background. Peralta-Nash (2003) considers home visits to be an important component of an intercultural learning experience that helps teachers better understand and get to know their students and families. In addition, Lynn and Bates (2010) found that home visits had a positive effect on a teacher's attitudes toward students of different backgrounds. Teachers become more compassionate, empathetic, and cheerful after visiting the home. Lynn and Bates additionally revealed the need to train service and service teachers to visit the home. As teachers learn the importance of helping students feel accepted by their home and 
educational culture, positive relationships with the school at home are strengthened through home visits, phone calls, contact books, and emails.

This study used seven learning strategies presented by Jackson in 1994 to help teachers understand the diversity of their students, families, and communities. "Strategies provide a basis for taking an active position in solving problems in teaching or educating entire generations of students with different cultures" (Jackson, p. 303). Although the challenges faced by classroom teachers are more complex than ever, the strategy for addressing these issues remains the same. In order to provide a culturally responsive and appropriate learning environment and curriculum, teachers need to know who their students are and what their problems, needs, worldviews, thoughts, and hopes for the future are. In fact, the aim of this study was to find out how teachers try to understand children and families in the community they teach in different ethnic groups, cultures, languages, customs, values, holidays, celebrations, rituals, and symbols. The main research question of this study was: What efforts are teachers making to understand the diversity of children and their families present in their classrooms?

\section{METHODOLOGY}

\section{Participants}

A convenient example was used to register participants in the study. Sixty teachers of school-age children participated in this study; all participants taught elementary classes ( $\mathrm{K}$ to 3). All participants live in a Midwestern village in the United States. The population demographics are approximately $77 \%$ white, 10\% black / African American, 7\% Asian, and 6\%
Hispanic / Latino (U.S. Census Bureau, 2010). The majority of the teacher participants were female, with only one male. The teaching years of the teacher participants ranged from five to 25 , and only one teacher was Black. About $85 \%$ of teachers taught in public schools and $15 \%$ in private schools.

Processes

An open conversation was used as part of a larger study that examined the beliefs of parents and teachers about home / school collaboration. In this study, open-ended questions were used to facilitate participants 'convenience and to develop a clear understanding of participants' experiences (Bogdan \& Biklen, 2002; Silverman, 2001). In this study, semi-structured interviews were used to obtain comparable data and to encourage participants to speak. The interview protocol was developed by the researchers, who sought to understand how parents in the United States participate in their children's school and what teachers do to understand and engage and understand the students and their families who make up their class. . This article focuses on one important question from that interview: how do you begin to understand the different ethnic groups, cultures, languages, customs, values, rituals, and symbols of the children and families in the community you teach? Teachers 'answers to the questions were coded and clear codes emerged from the analysis. The analysis process began with open coding of participants 'questionnaires. The methodology based theory defines open coding as the process of developing categories of concepts and topics derived from data. The study of data is carried out without prior assumptions about the relationship between what can be discovered and data that has not yet been identified. According to Bryman and Burgess (1994), 
"categories are rarely known before data are studied, and relationships between categories should always be identified during data analysis" (p. 168). Coding was performed by two researchers. The data analysis was divided into five main categories: classroom activities, personal experiences, personal actions, community activities, and school / district actions.

\section{RESULTS}

In the classroom, teachers need to be aware of the cultures designed to develop preparation with students who come from different countries to learn a language. It is important to know how his roots, heritage and customs and origins affect his teaching. Teachers need to be aware of the beliefs that underlie decision-making (Pajares, 1992; Richardson, 1996) because previous beliefs evoke classroom practice and these practitioners 'knowledge of students. great influence on the reception. Teachers may not be aware of their roots and behaviors, and may not be able to understand teachers 'tendencies and behaviors. Joshi, Eberley, and Conzal (2005) argue that having a deep understanding of the culture of teachers themselves or their students is a struggle to build a bridge between school and home. Kats (1993) examines the development of teachers 'self-awareness in terms of culture, arbitrariness, and discriminatory activities, and their impact on their development, attitudes, and expectations, as teachers deal with. One of the most important skills that teachers need to work with is to build on the knowledge that students bring into the classroom. There is a wealth of knowledge in the form of families, communities, and cultural histories. Unfortunately, neither parents nor students are used as a resource by the majority of participants in this study. Derman-Sparks and Ramsey (1999) work with parents to improve teachers 'work on overcoming Tajiks, allocating resources, and developing strategies. One of the strategies for using parents in the classroom is to invite parents to interact with guests and speakers on their own and children's experiences (Lake \& Lin, 2004). Parent educators can then provide specific strategies that can be implemented to meet the cultural, ethnic, racial, and special programs of their students. This is especially true when working with bilingual parents. In fact, the results of this study are represented in five main categories: classroom activities, personal experiences, personal use, community activities, and school / district actions.

\section{FINDINGS AND DISCUSSIONS}

In studying the data and the five categories produced, it is clear that all teachers in our study will make some effort to address the diversity of students in their classes. However, it was clear to see different levels of depth in addressing diversity in each of the categories. The two categories that responded the most were classroom activities and personal actions.

\section{Classroom activities}

Examples of classroom activities include children from around the world, group discussions, and student participation in their own cultural environment. The two different responses were to incorporate different cultures into the curriculum and to invite speakers to the lesson. But less than 25 percent of teachers mentioned both of these categories. This teacher included both in his response: "As a teacher, I find it important that I incorporate several cultural characteristics throughout my classroom 
activities. I am also sure to include books that discuss the languages, customs, values, rituals, and more of different cultures. I also encourage guest speakers to enter the classroom to discuss some of the cultures we have discussed throughout the year. "This teacher does not bring many specific features, but he does bring different cultures into his class. It is not clear whether these different cultures are actually represented by the students in his class or who the guest speakers are actually. Other teachers noted that they invited their own speakers, many of whom were their own. in the classrooms were the parents of the students. For example, one teacher said, "Parents come into the classroom and talk about their different holidays and customs." Previous quote and the like from the words "all ethnic holidays are discussed. In our library / computer time, children check and report on various winter holidays. "It is clear that many teachers do not know enough about different cultures to inform students about ethnic holidays or meals. provides information that probably does not take into account other important aspects of these cultures. We believe that these types of responses only reflect a superficial understanding of diversity and, in some sense, a superficial understanding of cultures.

As mentioned below, many teachers have used questionnaires to learn about their students 'culture, but the following teacher uses an interview format, but passes it on to their students. "At the beginning of the year, I interviewed students about their background and culture as a family member, and that tells me a lot. These traditions are associated with interesting things about their family's origins, who forms the family, who they live with, and their family. "Only seven of the teachers in the study asked students to make presentations about their culture, and a few of them mentioned teachers, including a group discussion on the content of these presentations. Some teachers said, 'I I tried to introduce different curricula so that students would be aware of the differences in the world and "I include sections dedicated to different countries and cultures" offered simple general classroom programs. teachers did not provide much information about what was included in the presentations and how they were directly related to their students and the teacher's perceptions of their students. Teachers discussed cultures only superficially Another piece of evidence is that most of the teachers pointed out that they placed or decorated the classroom on posters to showcase other cultures. once again, there is no clear discussion of how it was used in the big picture or how relationships were established with students in that class. Decorating a classroom to showcase other cultures can be a good start, but it is important to have an in-depth discussion of what these things are and why they represent a culture. Individual actions. The second most common category is personal actions, where teachers make personal actions to learn more about their students and / or different cultures. For example, several teachers said they would send parents to their homes to find out about their students 'backgrounds. One teacher said, "At the beginning of each new school year, I fill out a questionnaire to let all my parents know about their children, their families, their customs, their culture, and so on.". This teacher was more specific about what was included in the survey than others, for example: "At the beginning of the year, I send the survey completely voluntarily and voluntarily, but it asks questions about the field and the topic." This teacher also points out that the survey is completely voluntary, so she may not be able to get information about 
all her students, so be sure to miss out on some valuable information. Explaining to parents why this information is important to the teacher and how to use it may motivate more parents to respond to the survey. The following teacher seems to have a good understanding of what students want to learn from their parents. His answer means that he understands that diversity goes beyond the confines of a nation. "At the beginning of the year, I ask parents to fill out an interview. It consists of questions about their children's interests, etc., as well as what holidays they spent during the year, what holidays / celebrations they did or did not celebrate, what languages they spoke other than English, their family compositions, religious backgrounds output, community / school environment, etc. It serves me to learn more about each child and where they came from. I also ask them if they have anything they are willing to share with the class, such as how they celebrate the holiday / customs / meals, etc., which tells me more about where it comes from. helps me know I need information. a basic understanding of the culture of this family. "The teacher above also shows that she is trying to learn more about the culture and origins of the family by doing the necessary research. Unfortunately, this was only one teacher out of our sixty participants. Other teachers have also shown the importance of studying the families of their students, but have done so in other ways. For example, one teacher said, "I liked to ask parents about themselves and their culture at the first meeting, they usually want to share with them." This may be a good idea for him personally, but the first meeting often takes place at the end of the school year, in which case the teacher is deprived of many important opportunities for teaching and learning. 'may be. Another teacher said she learned about her students that "it's easy to taste student culture by visiting home". This teacher clearly understands the importance of getting to know the environment in which parents and students live. Visiting a home is a great way to explore many aspects of children, but one teacher even mentioned this opportunity. In addition to asking about students 'origins, several teachers focused on single-teacher behaviors that emphasized the importance of "modeling respect and appreciation for diversity". It was unclear how he expressed his appreciation for diversity. And another teacher, who undertook to learn more by reading about different cultures, said: "I am an avid student, so I have a diverse ethnic background through my readings. I will have general information about ethnic groups, customs, rituals and so on." Reading can be valuable, but teachers need to keep in mind that their students are still individual and may or may not be similar to what they read in the book.

\section{Personal experiences}

Three additional categories, personal experiences, school activities, and community activities occurred less frequently than classroom activities and personal activities. As for personal experiences, some teachers thought that their previous courses would help them understand their students: "I do a lot of cultural exercises to get to know the different ethnic groups I attend in my class each year. 'I took part in the class.' It is commendable that this teacher has conducted so many lessons, but most importantly, how she uses these lessons in her practice and does not find an effective solution in her response. Other teachers focused on their many years of teaching experience: "Because I have been a teacher at risk for 27 years, I am exposed to different ethnic groups, cultural backgrounds, languages, customs and rituals. 
I work well with and understand. " True, he may know a lot about different cultures, but it's not like how he addresses the fact that his students are individual and diverse in many ways beyond nationality and culture. Another teacher noted that there was very little ethnic diversity in her school, but because she is a member of this community, she is very familiar with the families and large families of many of her students: "Ethnic diversity in school very little community. Luckily I lived in this town. It allows me to be an active citizen and meet many school families. Before the students come to my class I know many families and even their big families. created a great opportunity to give an insight into the origins and traditions of each child. "Although, he points out the lack of ethnic diversity in his community, he is still reluctant to meet students and their families. Demonstrates that the view is important Community events. As for resources in the community, it was clear that teachers did not use these resources to obtain information about different cultures. Only one teacher mentioned everything about public resources, such as "I participate in cultural events in my community". He did not elaborate on what happened and how he connected them to his class and students. In many communities, teachers can participate in cultural centers or events to learn more about their students and the different cultures in the community, unfortunately these resources do not seem to be used by teachers. In addition to the five categories identified, the responses of some teachers to the question demonstrated their very limited views on diversity. The only African-American teacher explained that he "grew up in the inner city, everyone was in the same social class, so race wasn't a big deal". This means that he doesn't consider race to be an important issue in teaching, perhaps he has the idea that all children should be treated the same regardless of their background. He did not talk about any method he used to meet his disciples. Other teachers said, "I didn't really do anything this year because we don't have students with a big cultural difference," and "No, not really. [City name] Many" ethnic groups "or" cultural Both of these comments reflect the fact that the diversity of these teachers cannot go beyond ethnic backgrounds. Regardless of their ethnic origins and cultural differences, their students still have different beliefs, customs. and similarly derived from different families.

In schools / districts. Most of the participants in this study noted that they have tried to introduce other cultures into their curricula and integrate them. However, only a few knew how to do it. Being culturally literate is one of the strategies Jackson (1994) suggested that teachers work with students of all backgrounds. Recognizing that students of different backgrounds need to be multicultural or bidialectic to adapt to most schools, teachers need to be aware of their students 'language, values, social customs, and teaching styles ( Jackson). Districts and schools can support teachers who can organize study groups and workshops on different cultures that are students in those districts and schools. Schools / districts can and should invite parents in addition to professionals to share their culture and teach teachers some important phrases / words in their own language. It is understandable that a teacher who has no knowledge or experience of children and parents who are linguistically, culturally, and racially different from himself or herself is very strict in dealing with them. can feel. In addition, not all teachers have the knowledge and training to work with all children, especially those with special needs or ELL children. Thus, it is a huge investment for schools / districts to work with 
students with special needs and conduct inservice training on working with ELLs, as well as ongoing collaboration with home schools.

Providing in-service training / teaching to teachers can help teachers feel less overwhelmed when it comes to working with a diverse student population. Schools / districts should also encourage teachers who want to improve their academic performance, participate in conferences, seminars, and work more closely with parents. For example, home visits should be supported at the district level. In this study, only two of the 60 teachers visited their students 'homes. Peralta-Nash (2003) considers home visits to be one of the essential components of an intercultural learning experience that helps teachers better understand their students and families. In addition, Lynn and Bates (2010) found that home visits had a positive effect on a teacher's attitude toward students with different backgrounds. Teachers became more compassionate, empathetic, and harmonious. After realizing that their perceptions had changed in relation to their culturally diverse students, teachers sought ways to incorporate more of the students 'culture into the classroom, realizing that their knowledge had changed in relation to diversity and diversity. then, teachers sought ways to incorporate more of the students 'culture into the classroom, furthering their knowledge and tolerance for diversity and diversity. Many of these ideas are easily implemented in any classroom. However, the first thing teachers need to know is that their students and their families come in a variety of sizes, shapes, textures, and makeup (GonzaleMena, 2010). If teachers cannot understand their students, they cannot adapt education. For teachers to work effectively with all students, teachers need to know who they are in their classrooms. This goal can be easily achieved with the support of schools / districts. It appears that some participants in this study applied Jackson's (1994) many culturally responsive strategies in one way or another. However, we can argue that their good intentions have not been fully realized because of their limited knowledge of diversity and their unwillingness to teach all students. This type of extensive research across the United States helps us better understand that localization plays an important role in the readiness and readiness of teachers to teach all students.

\section{CONCLUSION}

In summary, this article shows that teachers in the Midwest in the United States may not be fully prepared to work in the different classrooms they face now or soon. Although in this study, teachers try to find out something about their students, they are often concerned about how they can learn and how to use this information effectively to teach their knowledge. they shake their heads. We think teachers all over the world are facing this problem. Teachers themselves are not to blame, they should be given the opportunity to be informed about the integration of diversity and diversity and diversity curricula into their classrooms, and most importantly, to educate teachers. in addition to offering a single diversity class, unit programs should, on the contrary, integrate diversity throughout all content courses. as well as. And, of course, preschoolers need to be taught the right ways to learn about students, learn about their culture, and go beyond skin color. All students in each class have something; it is the class teacher's job to determine what might happen. To achieve this, teachers need to get to know their students and the families of their students. Not only learning about other 
cultural or ethnic backgrounds from family resources, but also community resources, but also allowing children to see the value of the resources available to us, whether they are our parents, our community, or the class in which they sit. should be used for. next to. Anyone can suggest something. And the best thing is to include all students and their families in the learning process. As a result of this research, it is clear that there is a long way to go for many teachers to be culturally responsible as the world is more diverse than ever before, and we have the opportunity to innovate and collaborate for these teachers as well. we think that gives. With the support of colleagues, parents, students and administration, we hope this goal can be achieved.

This article also discusses how students with different backgrounds, experiences, ideas, and contexts relate to different aspects of target culture and what values they assign to target culture as part of learning foreign languages. may depend. One of the findings of the study showed that students in both groups generally understand the importance of teaching and integrating culture in a foreign language classroom. Also, the main goal of teachers in teaching culture in English teaching is to develop justice, honesty, patience, charity and tolerance towards the target culture. According to them, to acquaint students with the daily life of the target culture, to teach and acquaint them with the target culture and its traditions, peculiarities, rituals, customs, stereotypes, perception, lifestyle, values and norms. can cover the concept of Such an understanding is also seen as a way to allow students to explore their own cultural types and their cultural diversity. This attitude is consistent with what culturally responsive teachers do in the classroom. They use culture as a means of emphasizing the differences and similarities between different cultures and the speakers of those cultures. All teachers have some knowledge of aspects of target culture, but how they interact with target culture is influenced by curricula and limitations. One suggestion that follows from this conclusion is that teachers need to be given more opportunities to engage with the target culture in their classrooms. If they are more flexible in integrating the culture, students can improve more in terms of exposure to the target culture

\section{REFERENCES}

1. Aaroe, L., \& Nelson, J. (2000). A comparative analysis of teachers', Caucasian parents', and Hispanic parents' views of problematic school survival behaviors. Education and Treatment of Children, 23, 314-324.

2. Allen, J., \& Porter, O. (2002). Teaching about diversity issues. Kappa Delta $\mathrm{Pi}$ Record, 38, 128- 133.

3. Au, K., \& Blake, K. (2003). Cultural identity and learning to teach in a diverse community. Journal of Teacher Education, 54, 192-205.

4. Becerra, D. (2012). Perceptions of educational barriers affecting the academic achievement of Latino K-12 students. Children \& Schools, 34, 167-177. doi:10.1093/cs/cds001

5. Benson, B. (2003). Framing culture within classroom practice: Culturally relevant teaching. Action in Teacher Education, 25, 16-22. 
6. Bogdan, R., \& Biklen, S. (2002). Qualitative research for education: An introduction to theories and methods. Boston: Allyn \& Bacon.

7. Brown, E., \& Howard, B. (2005). Becoming culturally responsive teachers through service- learning. Multicultural Education, 12, 2-8.

8. Bryman, A. \& Burgess, R. (eds.) (1994). Analyzing Qualitative Data. London: Routledge.

9. Carrington, S., \& Selva, G. (2010). Critical social theory and transformative learning: Evidence in pre-service teachers' servicelearning reflection logs. Higher Education Research \& Development, 29, 45-57.

10. de Boer, H., Bosker, R., \& van der Werf, M. (2010). Sustainability of Teacher Expectation Bias Effects on Long-Term Student Performance. Journal Educational Psychology, 120, 168- 179.

11. Derman-Sparks, L., Ramsey, P. (2000). A framework for relevant ' multicultural' and antibias education in 21st century. In J. Roopnarine \& J. Johnson (Eds), Approaches to Early Childhood Education. Upper Saddle River, NJ: Merrill Prentice Hall.

12. Garmon, M. A. (2005). Six key factors for changing preservice teachers' attitudes/beliefs about diversity. Educational Studies, 38, 275-286.
13. Gay, G. (2002). Preparing culturally responsive teaching. Journal of Teacher Education, 53, 106-116.

14. Gay, G., \& Howard, T. (2000). Multicultural teacher education for the 21st century. The Teacher Education, 36, 116.

15. Gonzale-Mena, J. (2010). 50 strategies for communicating and working with diverse families. Upper Saddle River, NJ: Pearson.

16. Good, M., Masewicz, S., \& Vogel, L. (2010). Latino English language learners: Bridging achievement and cultural gaps between schools and families. Journal of Latinos and Education, 9, 321-339. doi: $10.1080 / 15348431.2010 .491048$.

17. Goulet, L. (1998, April). Culturally relevant teacher education: A Saskatchewan First Nations case. Paper presented at the annual meeting of the American Educational ResearchAssociation, San Diego, CA.

18. Hein, C. (2004). Color-blindness vs. race matters: Preschool education and the need for a communal vision. Multicultural Education, 11, 51-53.

19. Horm, D. (2003). Preparing early childhood educators to work in diverse urban settings. Teachers College Record, 105, 226-244.

20. Jackson, F. R. (1994). Seven strategies to support a culturally responsive pedagogy. Journal of Reading, 37(4), 298-303. 
21. Joshi, A., Eberly, J., \& Konzal, J. (2005). Dialogue across cultures: Teachers' perceptions about communications with diverse families. Multicultural Education, $13,11-15$.

22. Lin, M., \& Bates, A. (2010). Home visits: How do they affect teachers' beliefs on teaching and diversity? Early Childhood Education Journal, 38, 179-285.

23. Sleeter, C. (2001). Preparing teachers for culturally diverse schools: Research and the overwhelming presence of Whiteness. Journal of Teacher Education, 52, 94-106.

24. Ukpokodu, O. (2004). The impact of shadowing culturally different students on pre-service teachers' disposition toward diversity. Multicultural Education, 12, 19-28. 